\title{
La segunda generación de inmigrantes magrebíes en Francia
}

Presentamos en esta nota algunas reflexiones sobre las características más problemáticas de la segunda generación de origen magrebí y de su incorporación a la sociedad francesa contemporánea. Partimos de una descripción general del problema, en términos estadísticos y documentales. A continuación nos centramos en el comentario de una selección de textos de Leïla Sebbar, conocida - y muy influyente- autora francesa de origen argelino, en los que se refleja la importancia de la evocación del espacio vivido en el colectivo de origen norteafricano occidental instalado en Francia.

Durante la década de los sesenta se trasladaron a Francia numerosos trabajadores magrebíes varones, en solitario, cuyas mujeres y familias se incorporaron más tarde, durante los setenta, a raíz del cierre de fronteras laborales que siguió a la gran crisis petrolífera. La primera generación inmigrante magrebí se instaló en barrios singulares de las grandes ciudades francesas, con muy escasa interacción con la población autóctona. Como su presencia estaba vedada de facto en los espacios públicos, los inmigrantes se refugiaron en la proximidad de unos con otros; así surgieron los enclaves étnicos. Pero sus descendientes, con nacionalidad francesa en la mayoría de los casos, no han aceptado permanecer en semejantes condiciones y han intentado superar los obstáculos que los separaban de los que son sus compatriotas; pero, al hacerlo, se han convertido, consciente o inconscientemente, en un colectivo marcado. 


\section{INTRODUCCIÓN}

En Francia, según datos del INSEE, en 1999, la comunidad magrebí superaba los tres millones de habitantes, desglosados de la siguiente manera:

\begin{tabular}{lcccc} 
& Argelinos & Marroquíes & Tunecinos & Magrebíes \\
\hline Residentes extranjeros & 777.332 & 663.731 & 224.096 & 1.665 .159 \\
Nacionales, hijos de residentes extranjeros & 670.966 & 188.462 & 139.052 & 998.480 \\
Nacionalizados & 156.856 & 133.405 & 80.987 & 371.248 \\
Total & 1.605 .154 & 985.598 & 444.135 & 3.034 .887 \\
\hline
\end{tabular}

Fuentes: SOPEMI, 2001.

INE Recensement de la population, 1999. http://www.recensement.insee.fr

En París, la población magrebí ocupa un primer lugar, destacado, entre las comunidades de inmigrantes. Esto es cierto, a pesar de que el volumen de magrebíes residentes en la ciudad de París ha decrecido en los últimos años, debido a cambios de uso urbano que afectan a la ciudad central de la región "Ille-de-France". En 1990 residían en París 106.693 magrebíes, que constituían el $26,7 \%$ del total de residentes extranjeros en la ciudad. En 1999, la colonia magrebí reunía a 99.632 individuos, un 25,7\% del stock extranjero en la capital de Francia.

Si nos asomamos al Atlas des populations immigrés en Ille-de-France, publicado por iniciativa del INSEE, con la colaboración del Fondo para la Integración y para la lucha contra la discriminación, podemos apreciar con detalle los flujos más importantes y los patrones de asentamiento de las comunidades de inmigrantes más representativas, en el periodo 1982-1999. En "Ille-de-France" la mayoría de los inmigrantes viven en la ciudad de París y en la periferia más inmediata, donde se localizan la mayoría de las viviendas subvencionadas de la región. El departamento de "Seine-Saint-Denis", en esa primera corona concéntrica, al NE de la ciudad, es el que tiene una proporción de inmigrantes más alta. Los inmigrantes magrebíes se localizan, de manera mucho más concentrada que otros extranjeros, en los departamentos de "Hautes-de-Seine", en el primer cinturón, e "Yselines", en la segunda corona metropolitana, al oeste de la ciudad, próximos a los grandes complejos fabriles siderúrgicos, mecánicos, del transporte etc., que emplearon mucha mano de obra en los años sesenta. 


\section{LA REVUELTA URBANA}

Durante las últimas dos décadas, los barrios populares franceses se han convertido en el escenario de disturbios callejeros, protagonizados por jóvenes, en su mayoría de origen inmigrante. Incendios de decenas de coches, destrucciones de edificios públicos y enardecidos enfrentamientos entre los conocidos como "jeunes de banlieue" (jóvenes del suburbio) y las fuerzas del orden, se producen en los barrios más desfavorecidos y relegados de las grandes metrópolis francesas ${ }^{1}$.

Las primeras revueltas aparecieron en los barrios industriales de las ciudades del sur de Francia, coincidiendo con la fuerte crisis económica de finales de los años setenta. El desempleo aumentó entre los obreros veteranos y se bloqueó la entrada a las fábricas de los jóvenes no cualificados, descendientes, en su mayoría, de la inmigración magrebí, asentada en Francia entre las décadas de los sesenta y setenta. En la región de Lyon, MarseIla y Toulouse, durante los tres primeros años de la década de los ochenta, los jóvenes desataron su rabia contra todo aquello que representaba el Estado, con el objetivo de llamar la atención de los medios de comunicación y provocar un enfrentamiento con las fuerzas del orden.

La situación se hizo alarmante y la opinión pública comenzó a inquietarse. Pero, en medio del tumulto, algunos jóvenes y asociaciones se movilizaron para expresar sus reivindicaciones. Nació entonces un nuevo movimiento juvenil de protesta, el "Movimiento Beur" ("beur" quiere decir árabe en el lenguaje que se habla en los suburbios) que denunciaba el racismo y la situación de exclusión de muchos jóvenes, al mismo tiempo que exigía al gobierno una actuación y una reparación de las zonas urbanas más degradadas y castigadas por la crisis económica. Se celebró una gran Marcha que salió de Marsella bajo el lema: "Por la igualdad y en contra del racismo" y llegó a París con más de 100.000 personas. La movilización juvenil recibió un importante apoyo por parte de la ciudadanía y el gobierno reaccionó positivamente. Las peticiones de los jóvenes fueron escuchadas por el presidente Miterrand. Sin embargo, el paso de los años sólo trajo consigo la desilusión. El desempleo y la marginalidad juvenil aumentaron a principios de los años noventa. La juventud se sintió defraudada por los

1. Bachmann, C. (2002): Violences urbaines: ascension et chute des classes moyennes à travers cinquante ans de politique de la ville. París: A. Michel, 569 p. Khosrokhavar, Farhad (2000): "La violence et ses avatars dans les quartiers sensibles", Déviance et société, vol. 24, pp. 425-440. Wieviorka, Michel (2000): "Le nouveau paradigme de la violence", Cultures et Conflits, vol. 29-30. 
poderes públicos y la violencia volvió a los suburbios, adquiriendo, esta vez, una mayor intensidad en las regiones urbanas del sur y expandiéndose a otras zonas del país, como la periferia parisina o la región de Estrasburgo.

\section{LOS FACTORES DE LA VIOLENCIA ÉTNICA JUVENIL}

La violencia se desencadena en los suburbios franceses coincidiendo con tres importantes cambios del paisaje social y cultural de las ciudades francesas, alterando la vida y las costumbres de sus habitantes, en especial la de los sectores socialmente desfavorecidos.

Las últimas décadas del siglo XX se caracterizan por un cambio profundo en el sistema productivo, debido al aumento de la competencia internacional y a las nuevas formas de rentabilidad y productividad de las grandes empresas y corporaciones. Surge una nueva sociedad de servicios y la industria manufacturera pasa a un segundo plano, siendo reemplazada por las nuevas tecnologías o trasladada a zonas del planeta más rentables en cuanto a gastos de producción y mano de obra.

En los países de Europa Occidental, el mundo obrero se desvanece, no sólo el empleo en las fábricas, sino también la organización social y el sistema de integración específico que permitían a la comunidad obrera vivir en paz, tener esperanza y contar con una serie de valores sociales y una solidaridad que servían de apoyo a las personas más débiles y necesitadas. El barrio obrero sufre importantes trasformaciones. De un espacio donde los vecinos se conocían, se comunicaban y estaban al tanto de sus vidas, sus dificultades y problemas, se pasa a un espacio anónimo donde los ciudadanos se limitan a coexistir. El espacio intermedio entre lo privado y lo público adelgaza ostensiblemente, y el control espontáneo y la comunicación entre los vecinos se deterioran. El mundo popular se derrumba y con él desaparece un sistema de integración y autorregulación que permitía trasmitir los valores, las normas y las creencias de una generación a la siguiente.

El trabajo industrial aseguraba un bienestar socioeconómico y la lucha del movimiento obrero permitía crear un espacio de diálogo donde las clases más desfavorecidas podían reclamar, exigir, protestar y presionar a las clases dominantes a través del papel mediador del Estado. La lucha sindical, las huelgas, el asociacionismo, funcionaban como mecanismo de presión y permitían a la clase obrera defender una serie de derechos sociales, al mismo tiempo que le otorgaban una dignidad, dando un valor a su trabajo y 
reconociendo su utilidad social. Sin embargo, el fin del industrialismo hace inestables y precarios los puestos de trabajo y arrebata a las clases populares los instrumentos o mecanismos de denuncia y protesta que hacían posible el mantenimiento del contrato social.

El aumento de la marginalidad social y la irrupción de un nuevo tipo de violencia en las ciudades a partir de los años 80 son, en parte, producto de la descomposición del sistema de acción política que funcionaba en el periodo industrial. No es casualidad que las primeras revueltas urbanas estallaran en una de las zonas industriales más importantes del país (la región de Lyon), donde las consecuencias de la crisis fueron devastadoras y los jóvenes quedaron sin empleo durante largas temporadas, sin poder acceder a ningún instrumento político de reivindicación para reclamar sus derechos. La inexistencia de mecanismos de expresión y reivindicación, y la incapacidad de los jóvenes de construir un discurso que les ayude a canalizar la frustración que provoca sentirse excluido y despreciado, convierten al disturbio y a la violencia en instrumentos de protesta de estos jóvenes².

Francia ha sido, durante buena parte del siglo XX, un país que ha abierto sus fronteras a la inmigración de trabajadores del sur europeo (entre ellos, españoles, portugueses, italianos, etc.) y sobre todo de las antiguas colonias del norte de África, que dejaron sus países de origen para trabajar en las fábricas francesas. Durante temporadas más o menos largas, los obreros trabajaban y enviaban a sus familiares buena parte de sus ganancias, con la intención de regresar un día a sus países en mejores condiciones. La inmigración en esta época era principalmente económica y temporal, un porcentaje muy bajo de inmigrantes se instalaba de forma definitiva en Francia.

Sin embargo, a partir de los años setenta, las dinámicas migratorias y el destino de los trabajadores inmigrantes cambian. La crisis económica motiva hacia mediados de los años setenta una política de cierre de fronteras, se restringe la entrada de inmigrantes económicos y se favorece la reagrupación familiar. La inmigración cambia de naturaleza y su restricción produce un efecto inesperado: el asentamiento de una buena parte de la inmigración que llegó a Francia entre las décadas de los cincuenta y sesenta y la Ilegada de un número substancial de familias. La instalación definitiva de las poblaciones inmigrantes trae consigo el nacimiento de las nuevas

2. Bataille, Philippe (1998): "Le racisme dans le travail: enjeu pour la vie sociale et urbaine", Migrations Société, vol. 10, n 60, pp. 83-92. Bouamama, Saïd (2000): "Le sentiment de "hogra": discrimination, négation du sujet et violences", Hommes et migrations, vol. 1227, pp. 38-50. Touraine, Alain (1991): "Face à l'exclusion", Esprit, núm. La France des banlieues, pp. 7-14. 
generaciones, y con ellas, determinadas comunidades étnicas se hacen más numerosas y visibles en el espacio urbano. La coincidencia de la llegada de estos nuevos habitantes con el aumento de la inseguridad económica y el paro hace emerger el racismo en la sociedad y los inmigrantes comienzan a ser víctimas de tratos discriminatorios.

\section{LA PROBLEMÁTICA DEL HÁBITAT}

Una vez dibujado el marco de la inmigración francesa reciente, especialmente la de origen magrebí, nos enfrentamos con los comentarios de algunos textos de Leïla Sebbar. Así contextualizados, los párrafos de Sebbar adquieren una significación original.

En el proceso de integración de la comunidad magrebí, su visibilidad en el espacio público juega un papel primordial, como causa y a la vez efecto, y también indicador, de la segregación étnica y social existente. En Francia, los asentamientos magrebíes se localizan en bolsas de tejido urbano degradado, o, más frecuentemente, en la "banlieue", en la periferia de las grandes ciudades, como París o Lyon. Ocupan zonas abandonadas por la población que asciende profesionalmente, cambiando de domicilio. El barrio se hace cada vez más étnico y así lo reflejan las psicologías colectivas de los "de dentro" y de los "de fuera". La aparición del ghetto, del "quartier-coussin", es el resultado de una construcción social. La segregación residencial es siempre más radical que la segregación basada en la categoría socioprofesional. Cabe preguntarse ¿Es posible compaginar la segregación residencial y la integración social de las comunidades de inmigrantes que tienen un carácter étnico muy diferenciado del de los nacionales y del de otros colectivos de inmigrantes?3.

El asentamiento de los inmigrantes magrebíes en las "banlieues" francesas más desarrolladas ha introducido una dimensión étnica en unos espacios que, con anterioridad sólo tenían un significado socioeconómico. Por eso, aunque bien justificadas, la actuaciones públicas de mejora de las infraestructuras en ciudades conocidas como "calientes" (Vénissieux, les Minguettes, Vaux en Velin, etc.) no han conseguido atenuar la conflictividad de esos distritos. Lo que desde el punto de vista inmobiliario se contemplaba como

3. Kepel, Gilles (1987): Les banlieues de I'Islam: naissance d'une religion en France, París: Seuil, 423 p. Khosrokhavar, Farhad (1996): "L'universel abstrait, le politique et la construction de l'islamisme comme forme d'altérité", en Michel Wieviorka, ed., Une société fragmenté? Le multiculturalisme en débat, París: La Découverte. 
la mera ocupación y adquisición de viviendas baratas en solares marginales, ha ocasionado, en el plazo de una generación, uno de los conflictos territoriales franceses más importantes.

Los marxistas y estructuralistas explican la segregación que contemplamos recurriendo a causas de tipo económico. Los culturalistas conceden mayor importancia a los vínculos étnicos, que se ven reforzados en las grandes aglomeraciones urbanas. El personalismo considera la segregación como una oportunidad de protección de la relativa autonomía individual. No existe una oposición radical entre estos cuatro tipos de explicaciones, que se enfrentan con un escenario migratorio fluctuante. Las actuaciones urbanísticas, en cambio, han optado por planteamientos más sencillos, a veces simplistas, confirmando la segregación existente mediante leyes, o planes, de zonificación de usos del suelo. En la mayoría de los casos, la zonificación ha fijado las fronteras intraurbanas, con la degradación progresiva de la vivienda en los distritos populares internos; en otros casos, se ha expulsado a las poblaciones inmigrantes de sectores periféricos, para el establecimiento de familias de clase alta y media-alta. Esta nueva zonificación es la que se corresponde con una ciudad terciarizada, y residencialmente suburbanizada.

En su evolución reciente, la gran ciudad francesa, en tanto que europea $y$, por ello, occidental, se consolida como lugar de concentración de diferencias radicales (ya sean culturales o, etnoculturales), convirtiéndose en un lugar de fricción. Es un zona vacía en la que la referencias desaparecen, acrecentando el malestar difuso en la relaciones entre las comunidades. Nos enfrentamos a un proceso de creciente anomia, que los medios reflejan cada vez con más frecuencia y que la política y la publicidad intentan explotar al máximo.

\section{LA ORGANIZACIÓN DEL ESPACIO EN EL BARRIO MAGREBÍ}

En el "quartier-coussin" la plaza es el lugar central. Funciona como un espacio semipúblico, donde se relacionan los individuos que viven en la vecindad, pero sin la presencia de los habitantes de la gran ciudad de la que forman parte. En el relato de Sebbar, "Fatima ou les algériennes au squar"4, se describen las relaciones que se construyen en la plaza. Las plazas son, la mayor parte del día, espacios segregados de los procesos productivos, frecuentadas por

4. L. Sebbar: "Fatima ou les algériennes au square", p. 60 y ss. 
mujeres, niños y ancianos, en ausencia de los varones y de las mujeres que trabajan fuera del barrio; se describen los procesos de paisanaje, vecindad, etc. En la plaza tienen lugar los procesos de socialización, y, entre los adolescentes, de enfrentamiento. El relato se componen de un conjunto de historias de vida que la autora colecciona con vistas a su intento principal de adecuación de modelos culturales antitéticos, o, en otras palabras, de presentación del triunfo de la identidad de la diferencia.

En el segundo relato, "Parle mon fils, parle à ta mère", la autora presenta cómo el barrio urbano magrebí materializa la alienación psicológica y social de la juventud, que romperá con ese mundo, a pesar de que es el que les ofrece una identidad al alcance de la mano. Su vida será una continua fuga hacia delante, cuyas primeras etapas serán las aglomeraciones urbanas o la capital parisina, con un gran riesgo de colapso en los nuevos espacios multinacionales. Gracias a la ocultación de un apellido, que parece pronto remoto, o al anonimato de las grandes metrópolis, los jóvenes intentarán la ascensión de la pirámide social. Sus puntos de referencia, sus símbolos de libertad y de triunfo en un momento inicial, se convertirán en muchos casos en catalizadores de una marginación próxima a la decadencia.

Se marcharán, pero algunos volverán al barrio. Allí se encontrarán de nuevo con su madre, que representa a la vez la ternura y el fracaso. El fracaso de los héroes, hijos de magrebíes, en un mundo que los arrumba, cuando menos. La vuelta al barrio va unida a la mención del cementerio, una especie de muerte anticipada, de tributo del orden social.

"Je suis allée de mon village de l'intérieur à ces cités et je ne sais pas aller de mon bloc jusqu'au train pour aller en ville. Je vais mourir ici, sans bouger..."

El perímetro urbano y el familiar materializan la alienación psicosocial de la joven generación magrebí en Francia. En contrapunto con los espacios de la decepción en la literatura sebbariana se recortan algunos decorados sublimados (barrios populares, marginales o extranjeros), que representan lugares de descanso y, también, de formación de los sujetos implicados.

\section{LA OCULTACIÓN}

Los inmigrantes solteros obreros y sus familias se caracterizaron siempre por una cierta invisibilidad. Confinados en viviendas en espacios definidos, lo más alejados posible del espacio público. En palabras de Sebbar: 
"Los edificios se organizan a manera de claustro, protegido, donde los coches no pueden entrar. Ellas permanecen tranquilas"

Entre la primera generación, confinada en las pensiones, hostales y tugurios, y la segunda, resultado del reagrupamiento familiar de los 80 , hay una diferencia observable en sus niveles de participación ciudadana, que aumentan en la segunda generación. Esta generación de refresco va a ensayar pautas de integración en la sociedad autóctona, relajando los vínculos grupales e invirtiendo en el espacio externo, fuera del barrio. Aunque en la infancia permanezcan en el barrio étnico, en la adolescencia empezarán las fugas cada vez más prolongadas, en fines de semana y tardes de primavera y verano, hacia el centro de la ciudad:

"Sa mère l'autorisait le samedi après-midi, parfois le mercredi à aller chez une copine...Mais elle ignorait tout de ses après-midi à Paris..."

El polo de atracción principal de los jóvenes es el centro de la ciudad, que permite el anonimato y la realización del individuo: un escalón más allá hacia la ruptura de los verdaderos lazos comunitarios. Los adolescentes magrebíes salen de su casa para no volver hasta la hora de comer, si realmente tienen hambre, o hasta la hora de dormir, y no siempre.

En muchos casos los adolescentes se recogen en lugares de poca visibilidad: cuevas, aparcamientos, descampados:

"Les garçons de la cité, les grands avaient leur coin où personne ne s'aventurait, pas même les petits frères et sœurs... c'était un territoire sacré et dangereux, que les habitués du square respectaient..."

\section{LA APARICIÓN DE UN NUEVO GRUPO}

Existe un cierto paralelismo entre el modelo sociocultural de incorporación de los inmigrantes, nacionales y extranjeros, en la región urbana de acogida y el modelo conocido del éxodo rural que engrosa las filas del proletariado urbano.

Sebbar tiene sus propias opiniones al respecto. Primero, que los inmigrantes no están integrados y no forman una comunidad. Carecen de la energía necesaria para proteger a su propia prole. Por eso, los hijos de los inmigrantes violentarán la sociedad francesa, por tanto que la sociedad 
francesa ha hecho violencia a sus padres, aquí y allá. Mantendrán una relación de amor y odio con la sociedad de acogida.

Les immigrés ne forment pas une communauté. Ils sont divisés, faibles dans I'incapacité de protéger leurs propres enfants. Ils vivent en déportation analphabète... ${ }^{5}$.

Les enfants de l'immigration feront violence à la France, comme elle a fait violence à leurs pères ici et là-bas...ils auront avec la France une histoire $\mathrm{d}^{\prime}$ amour mêlée de haine perverse et souvent meurtrièré .

Siempre según Sebbar, los hijos de los inmigrantes magrebíes han nacido en una crisis, que consiste en una mutación socioeconómica generalizada, presidida por una cultura monopolística globalizante. Los sistemas racionalizados de producción destrozan la clase proletaria de la que forman parte los inmigrantes magrebíes. Estamos en presencia de una grave crisis de identidad.

Lo jóvenes magrebíes viven una violencia cotidiana, que se combina con una crisis económica importante. Por este motivo, muchos jóvenes magrebíes han optado por una "visibilidad marginal", que se consolidará por el respaldo de los medios de comunicación social y de las instituciones públicas.

Los hijos de los inmigrantes han tenido el mérito de hacer públicas las reivindicaciones y los agravios de las comunidades magrebíes en Francia. Los jóvenes han conseguido salir en la televisión, dando una imagen diferente de la habitual, que es la de una población amorfa y poco cualificada. Estos jóvenes han conseguido que la noticias de carácter étnico hayan pasado de la sección de sucesos de los periódicos, a las primeras planas de los rotativos y a la polémica parlamentaria más sensible.

La segunda generación inmigrante, antes de cuestionar las actitudes y valores de sus ancestros, está intentando establecer un diálogo sincretista, plagado de referencias propias, con toda la sociedad de acogida. Ese diálogo tiene un cariz agresivo, que lo diferencia claramente del practicado por la primera generación.

La segunda generación aparece frecuentemente estigmatizada. Esas marcas pueden ocultarse pudorosamente durante algún tiempo, pasado el cual puede producirse una reacción más o menos violenta, que a veces se

5. L. Sebbar: "Lettres parisiennes", p. 123.

6. Ibíd., p. 60. 
convierte en la única manifestación de identidad. Antes de llegar a esos extremos, que no tienen por qué producirse en todos los casos, las actitudes de la juventud se reflejan en la forma de vestir y en cualquier otra dimensión que les permita expresarse de manera cosmopolita.

La nueva generación necesita, al menos, reconstruir una mitología de sus orígenes, arbitrar una vía de escape —o alienación- de lo cotidiano y negociar un proyecto social viable. Todo ello explica el afán de los jóvenes magrebíes por adquirir un estilo propio, que la sociedad reconozca y, de alguna manera, sancione.

\section{LA IDENTIDAD ÉTNICA}

En el mundo anglosajón las culturas étnicas han permito aglutinar a los miembros de las comunidades minoritarias inmigrantes, blindándoles, en cierto modo, de la presión mayoritaria. En ese espacio existen instancias intermedias entre el individuo y la totalidad de la sociedad. No es necesario que se postulen como tales, pero sí que no se persigan de manera normativa.

En el caso francés, en cambio, se proclama inexorablemente la igualdad de todos los ciudadanos de la república, pero excluyendo de tal colectivo a los que "accidentalmente" no lo son, aunque tengan su residencia en el territorio nacional. Este modelo ha funcionado en su ámbito hasta la etapa poscolonial, en la que nos encontramos. En la Francia poscolonial empiezan a destaparse actitudes "americanizantes", en las que no falta la defensa de la identidad grupal, así como la resurgencia del "proselitismo etnocultural", muy distinto del asimilacionismo de corte republicano.

Hay muchos indicios de que se ha producido un cambio radical de las condiciones de partida de la convivencia en la sociedad francesa de finales de siglo XX y principios del XXI. El más importante, sin duda es el bloqueo de la inserción profesional. El modelo republicano francés integrador, en la práctica, ha dejado de serlo, ya que mantiene excesivas inercias, excesivas tradiciones. En semejante circunstancia, la lucha por la propia identidad se descubre como frente social de primera magnitud.

Francia parece asumir, cada vez más, su condición de país de inmigrantes, al menos desde el punto de vista simbólico, ya que hasta ahora sólo se contemplaba la concesión del estatus de ciudadano, de vocación universalista, a los residentes extranjeros establecidos. En el discurso 
francés se descubren cada vez más ecos de políticas anglosajonas, más flexibles en lo cotidiano, pero incompatibles, hasta ahora, con la hipotética acogida sin condiciones. No se puede ignorar que las limitaciones a la integración de inmigrantes en el tejido nacional es un tema explosivo (el debate sobre la nacionalización automática de los jóvenes magrebíes es un ejemplo). El mito construido en torno a los valores republicanos no tiene ya mucho sentido. A su sombra se reactiva el pensamiento conservador y se impulsa una cultura tradicional, en un marco que difícilmente consigue ocultar sus propuestas étnicas con principios culturales.

Podría decirse que Francia, navegando entre los remolinos que ha generado la alteración del orden económico mundial, debe tratar con más tacto a sus huéspedes magrebíes, heredados de la situación poscolonial. Con una población cada vez más cosmopolita, el problema de la población de origen magrebí en Francia puede reproducirse con facilidad.

Sin olvidar que la gran dificultad del momento actual en Francia es la necesaria reducción de la masa laboral, y los criterios que la orienten, podemos hablar, en términos globales, de las inconsistencias de una inmigración que es hija del colonialismo del XIX en el seno de una sociedad nacionalista enfrentada a un mundo globalizado en el que las fronteras, si las hay, son de carácter totalmente distinto, fundamentalmente socioeconómico. Por otra parte, la protesta magrebí, que adopta tintes de identidad, se debe, principalmente, a la dificultad de inserción socioeconómica de la segunda generación.

\section{EN EL SENO DE UNA CULTURA DEL CONSUMO}

El cambio cultural definitivo ha sido el triunfo del consumismo. Las sociedades modernas se reducen al fin y al cabo a una serie desmesurada de circuitos de consumo diversificado, que convierten la relación entre los hombres en términos, desenfocados, de posesor y desposeído. En esta cultura lo único que no se puede ser es pobre, aunque sea a costa de la pobreza de los demás. Las relaciones interpersonales se hacen mucho más directas, porque están basadas principalmente en la adquisición en el mercado del objeto deseado y en la posesión del elemento escogido. En ese mundo la diferencia étnica ha sido asimilada como objeto de intercambio, de publicidad y de moda. Nos encontramos ante un problema más complicado de lo que parecía. En las sociedades occidentales, en que los medios de 
comunicación social intentan fabricar una cultura de masas, con una apariencia juvenil y mestiza.

La sociedad dominante trata la diversidad misma de acuerdo con los criterios de accesibilidad de todo para todos. De esta manera se arrasan las diferencias que existían, en aras de un mundo culturalmente más atractivo, sometiéndose la diversidad étnica o cultural al principio de difusión generalizada. Todas las diferencias aparecen virtualmente integradas, porque, teóricamente, no existe oposición dentro del modelo omnímodo legitimado.

Se buscan personajes exóticos para anunciar objetos fabricados en serie en los sótanos de la gran ciudad, o en plantas ordenadamente establecidas en polígonos industriales cercanos. La ortodoxia es multicultural. La cultura dominante trata la diversidad de manera que puedan ser accesibles sus componentes a cada uno de los miembros de la colectividad.

"L'orthodoxie est multiculturelle, elle joue toutes les cartes, la culture dominante traite de la diversité même selon des méthodes qui rendent toutes les différences accessibles à chacun..."

\section{Conclusiones}

Mientras la nueva clase urbana multicolor empieza a ser recogida y relanzada por los medios de comunicación institucionales, en las calles de las ciudades francesas se pasea una generación mestiza, que, como la parte visible de un iceberg, anuncia cambios drásticos de la sociedad tradicional.

"Ces bandes de jeunes métèques étaient peut-être porteuses d'un courant nouveau, il ne fallait pas les négliger on ne sait jamais, il faut rester branché dans ces métiers de la représentation, de la comédie sociale"7.

Lo étnico-cultural se hace publicidad, que trata de captar las voluntades de apropiación de las nuevas generaciones. Apropiación del otro bajo un aspecto culinario, intelectual, afectivo, o irreal. La apropiación instantánea de un objeto satisface, pero de manera efímera. Por ello, la

7 . L. Sebbar: "Shérazade", p. 117. 
integración que se fundamenta en la transacción comercial resulta tremendamente artificial; es muy frágil y necesitada de apoyaturas simbólicas, como la reinvención de la historia o la política, derivadas de los grupos intelectuales afines.

M'hamed Wahbi

ORMES,

Faculté des Lettres et des Sciences Humaines, Université Ibn Zohr, Agadir, Marruecos

Juan A. Cebrián Instituto de Economía, Geografía y Demografía, CCHS, CSIC, Madrid, España 